\title{
Novel Cover Screw Design for Flapless Stage II Surgery
}

Keywords: Stage II surgery; Minimally invasive; Cover screw location

\section{Abstract}

This case report demonstrates the use of an innovative cover screw and a Conical Explant Kit at the second stage surgery. The technique is minimally invasive, preserves the keratinized tissue, and reduces the patient's discomfort and treatment time.

\section{Introduction}

Dental implants can be placed either using a one stage (nonsubmerged) or a two-stage (submerged) surgical technique [1]. The choice is dependent on the surgeon's preference, presence of primary stability, need for a provisional restoration or simultaneous augmentation procedure $[2,3]$. With a one-stage procedure, a healing abutment or a provisional restoration is placed at the time of surgery. The one-stage approach avoids additional surgical intervention; hence it shortens treatment times and is preferable in the case of excellent implant stability (implants placed with insertion torque $>32 \mathrm{Ncm}$ ) [4]. With a two-stage procedure, the implant is submerged under the soft tissue. The rationale for the two-stage procedure is to reduce introduction of bacterial infection during healing, to prevent apical proliferation of mucosal epithelium along the titanium surface, and to minimize premature loading [5]. A second-stage surgery is performed to expose the implant for abutment connection following a period of undisturbed healing. Flap elevation is usually necessary to ease the identification and removal of the cover screw. Flap elevation usually requires sutures for wound healing which further prolongs the treatment time and increase the patient's discomfort.

This article aimed to introduce an innovative and minimally invasive second stage surgical technique that allows for easier manipulation of the soft tissue, preserves the keratinized tissue, and reduces the patient's discomfort and treatment time. The technique, described step by step below, utilizes a Conical Explant Kit (CEK) paired with a novel cover screw (Figures 1-3). Unlike most conventional cover screws that are either convex or flat, the unique concave top portion of the proposed cover screw facilitates its localization through the soft tissue. Additionally, the internal slot increases the friction between the CEK and the cover screw allowing its removal without any incision or a minimal one. Thus, preserving the keratinized tissue for immediate provisionalisation.

\section{Technique}

A standard clinical protocol was followed for the implant placement and a minimally invasive stage II protocol was used:

1. Following the administration of local anesthetic infiltration, a crestal incision and intrasulcular incisions on the mesial and distal aspects of neighboring teeth were performed and a full thickness muco-periosteal flap was raised (Figure 4).

\section{Journal of Oral Biology}

\section{Aikaterini Georgantza*, Eirini Paroutoglou, Yung Cheng Paul Yu, Mazen Natour and Edgard EI Chaar}

Department of Periodontology and Implant Dentistry, New York University, USA

\section{*Address for Correspondence}

Aikaterini Georgantza, Department of Periodontology and Implant Dentistry, New York University, Clinic 5W, 345 E 24th St, New York, NY 10010, USA, Tel: +1-917-767-9166; E-mail: ag4222@nyu.edu

Submission: 17 May, 2017

Accepted: 16 October, 2017

Published: 24 October, 2017

Copyright: $\odot 2017$ Georgantza A, et al. This is an open access article distributed under the Creative Commons Attribution License, which permits unrestricted use, distribution, and reproduction in any medium, provided the original work is properly cited.

2. The osteotomy was made with an aid of a surgical stent made from an ideal wax-up for optimal angulation and position (Figure 5).

3. An implant was placed into the existing native bone (Figure 6).

4. The modified cover screw was placed and a periapical radiograph was taken to verify the seating of the cover screw (Figures 7 and 8).

5. Tension free primary closure was achieved with interrupted sutures using resorbable 4.0 chromic gut (Henry Schein, Melville, NY, USA) (Figure 9). The patient was monitored with routine follow-up appointments during the next 2 months.

6. After 2 months of undisturbed healing, the minimally invasive second stage surgery was performed. With the use of the Conical Explant Kit (CEK) the unique concave top portion of the cover screw can be easily traced through the soft tissue and removed a traumatically (Figures 10-12).

7. A healing abutment or a temporary abutment can be used at this stage (Figures 13 and 14) without the need for suturing.

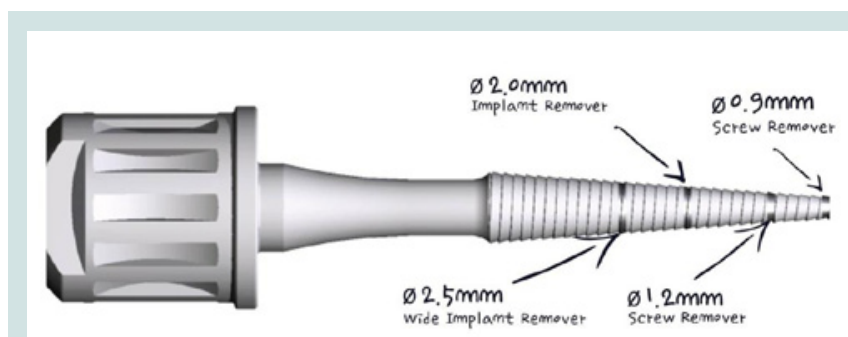

Figure 1: The versitile Conical Explant Kit (CEK) can be used toremove stripped screws, ruptured external or internal connection implants, locate and remove the concave cover screw at the second stage surgery. 


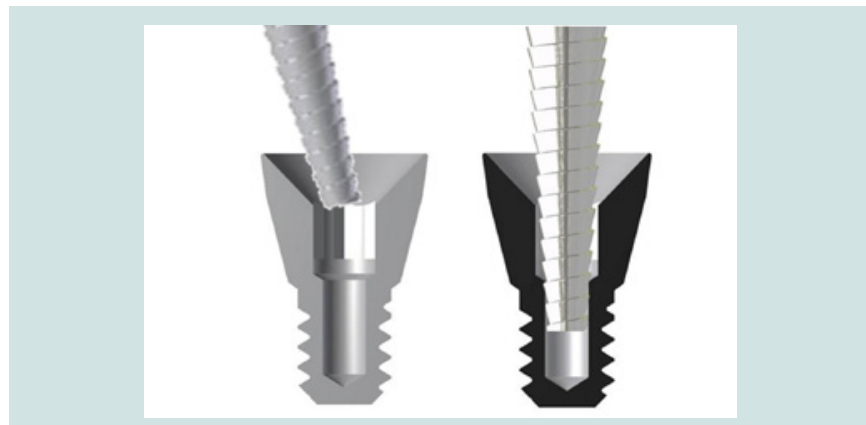

Figure 2: The concave top portion of the cover screw is designed for an easy localization at stage 2 procedure (Left image). The internal slot increases the friction between the CEK and the cover screw allowing its removal without or minimal incision (Right image).

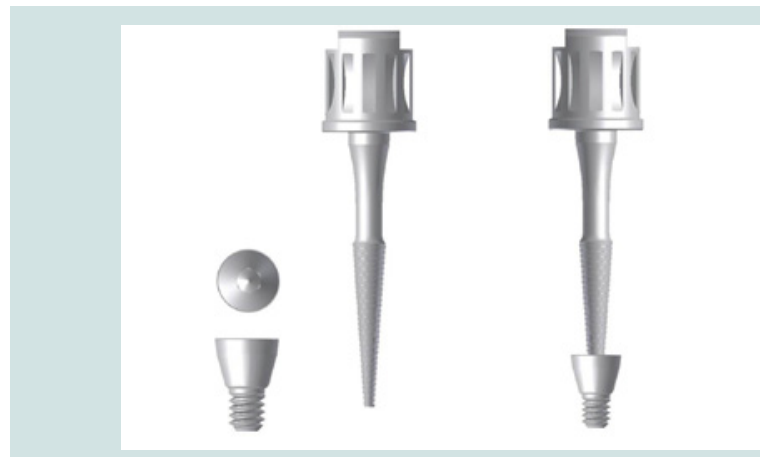

Figure 3: Example of a modified cover screw and the paired CEK. The modified cover screw is conical in shape to facilitate removal. The CEK securely engages the internal threads of the cover screw.

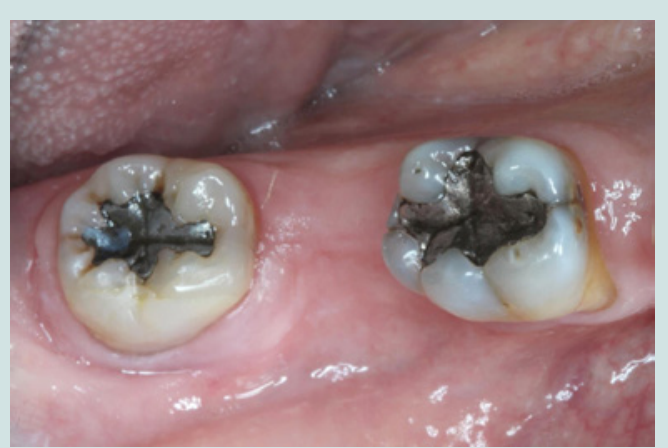

Figure 4: Pre-operative occlusal view of the edentulous mandibular right second molar site.

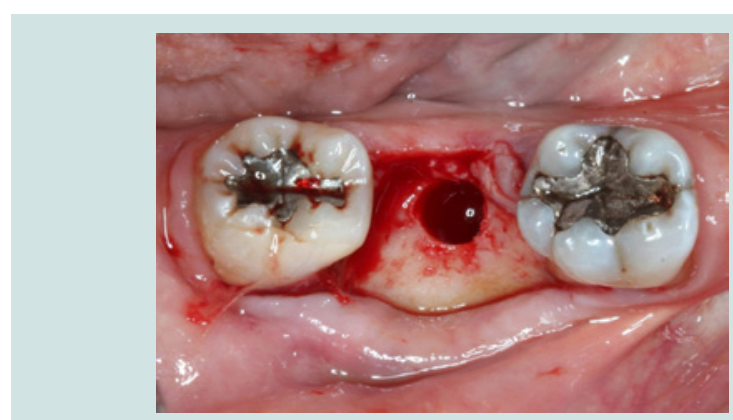

Figure 5: Osteotomy site prepared according to the manufacturer's protocol following the flap elevation.

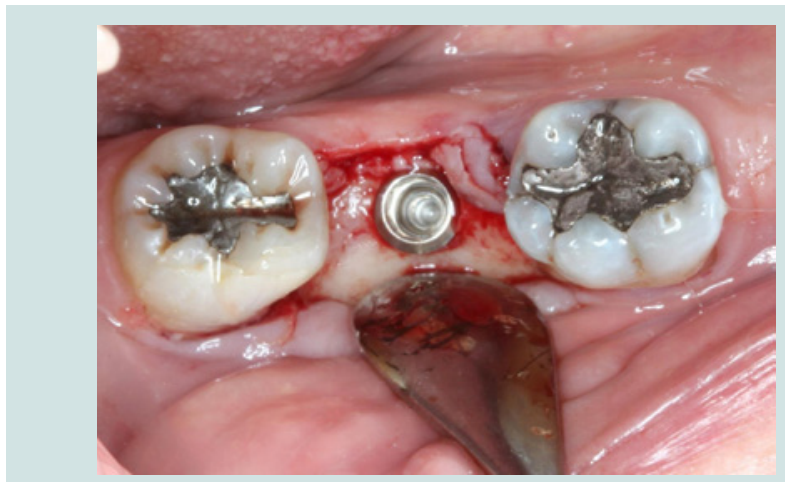

Figure 6:A dental implant was placed into the prepared osteotomy site.

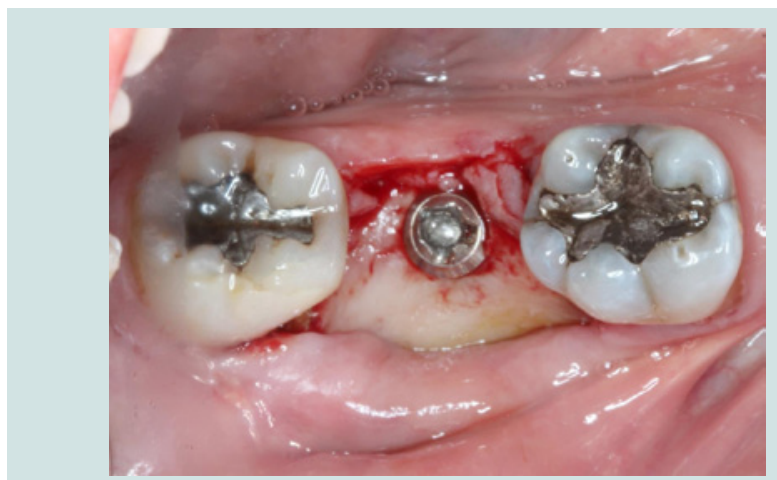

Figure 7: The modified cover screw was placed.

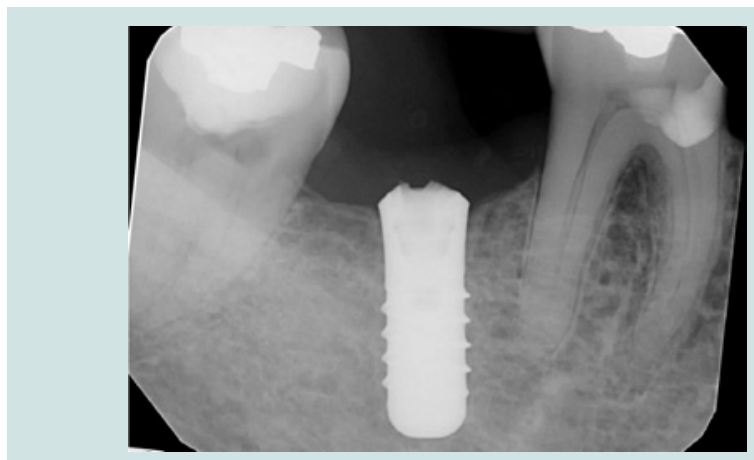

Figure 8: Periapical radiograph was taken to verify the seating of the modified cover screw.

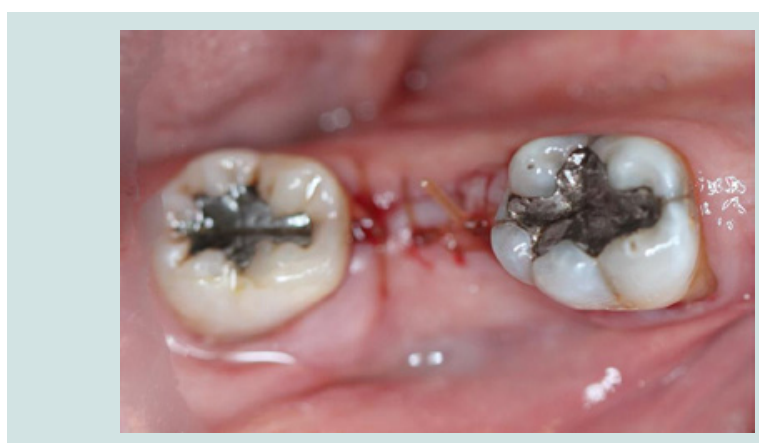

Figure 9: The implant was submerged and flap was closed with interrupted sutures. 


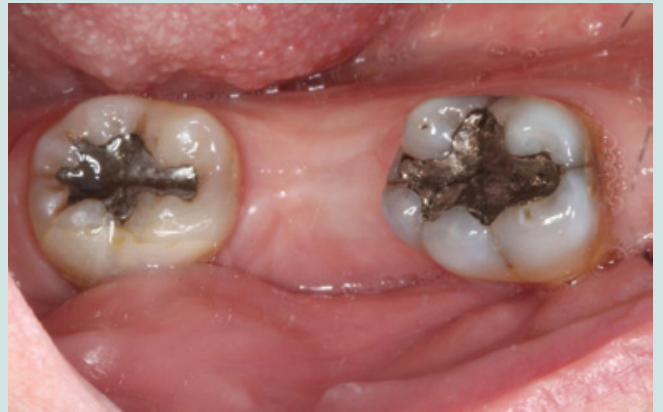

Figure 10: Pre-operative view following two months of undisturbed healing

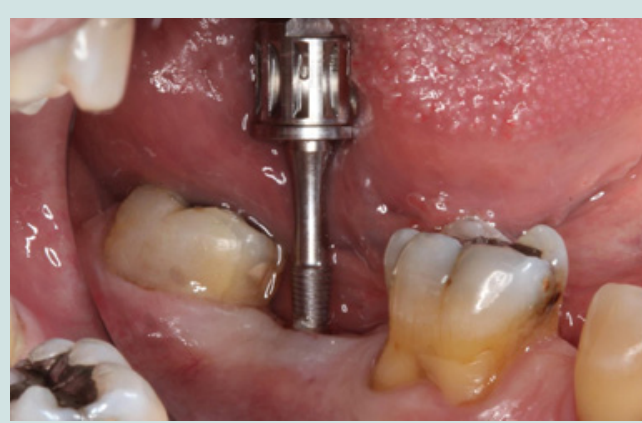

Figure 11: The Conical Explant Kit was used to identify the modified cover screw through a minimal incision. Due to the friction grip between CEK and the cover screw, the cover screw can be removed easily without disengaging from the CEK.

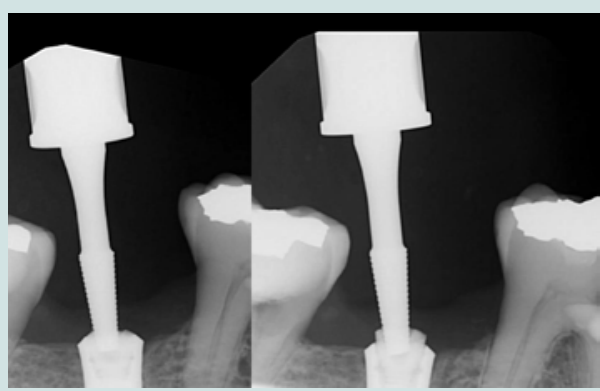

Figure 12: Periapical radiograph demonstrated the engagement of CEK and the modified cover screw $(\mathrm{L})$. Periapical radiograph demonstrated the removal of the modified cover screw through the soft tissue without dislodgement(R).

Table 1: Comparisons between 1- and 2-stage implant placement and conventional two-stage and innovative modified approach.

\begin{tabular}{|c|c|c|c|}
\hline & \multicolumn{2}{|c|}{2 stage implant placement } & \multirow[b]{2}{*}{$\begin{array}{c}1 \text { stage implant } \\
\text { placement }\end{array}$} \\
\hline & $\begin{array}{c}\text { Conventional } \\
\text { two-stage } \\
\text { protocol }\end{array}$ & $\begin{array}{c}\text { Innovative } \\
\text { modified } \\
\text { approach }\end{array}$ & \\
\hline Incision & Yes & No & No \\
\hline $\begin{array}{c}\text { Control of keratinized } \\
\text { tissue }\end{array}$ & Yes & Yes & No \\
\hline Suture & Yes & No & No \\
\hline Additional grafting & Yes & No & No \\
\hline $\begin{array}{l}\text { Insertion of provisional } \\
\text { restoration }\end{array}$ & No & Yes & Yes \\
\hline
\end{tabular}

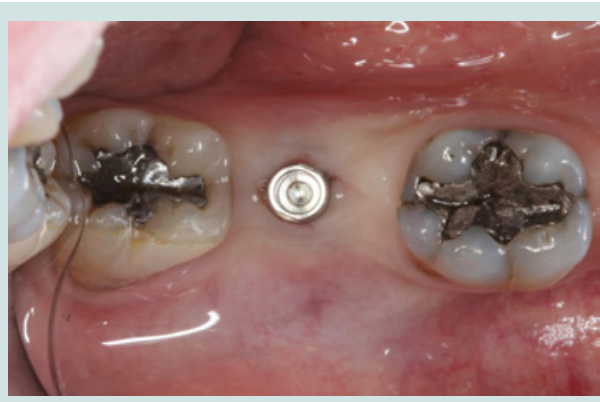

Figure 13: A healing abutment was connected to the implant, noting the minimal invasiveness of the procedure. No sutures were required since no flap was elevated.

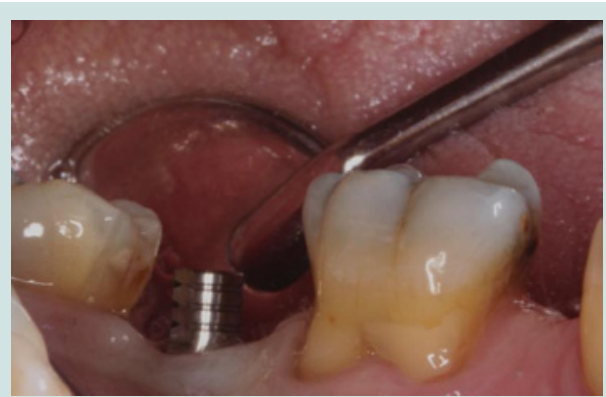

Figure 14: The minimal invasiveness of the procedure enabled the construction of provisional restoration at the second stage with ease.

\section{Discussion}

The innovative technique proposed in this article aimed overcome the drawbacks and maximize the benefits of the two-stage implant placement (Table 1). The Conical Explant Kit (CEK) driver can precisely locate the innovative cover screw and atraumatically retrieve it through the overlying tissue with a forceful movement coronally without the need for flap elevation. This is achieved by the friction between the internal slot of the cover screw and the uniquely designed CEK (Figure 1). The concaved shape of the cover screw also facilitates removal without trapping underneath the soft tissue. With the present technique and instrumentation, flap elevation and subsequent suturing at the second stage are no longer necessary, the keratinized mucosa is preserved and scar tissue formation is prevented. This significantly improves patient comfort and acceptance. Moreover, the insertion of the provisional restoration at the second stage can be achieved with greater control, producing the appropriate emergence profile and optimizing the outcome of the final prosthesis.

\section{References}

1. Becker W, Becker BE, Ricci A, Bahat O, Rosenberg E, et al. (2000) A prospective multicenter clinical trial comparing one- and two-stage titanium screw-shaped fixtures with one-stage plasma-sprayed solid-screw fixtures. Clin Implant Dent Relat Res 2: 159-165.

2. Cordaro L, Torsello F, Chen S, Ganeles J, Bragger U, et al. (2013) Implantsupported single tooth restoration in the aesthetic zone: transmucosal and submerged healing provide similar outcome when simultaneous bone augmentation is needed. Clin Oral Implants Res 24: 1130-1136. 
Citation: Georgantza A, Paroutoglou E, Yu YCP, Natour N, El Chaar E. Novel Cover Screw Design for Flapless Stage II Surgery. J Oral Biol. 2017; 4(2): 4.

\section{ISSN: 2377-987X}

3. Hammerle $\mathrm{CH}$, Jung RE, Sanz M, Chen S, Martin WC, et al. (2012) Submerged and transmucosal healing yield the same clinical outcomes with two-piece implants in the anterior maxilla and mandible: interim 1-year results of a randomized, controlled clinical trial. Clin Oral Implants Res 23: 211-219.

4. Esposito M, Grusovin MG, Chew YS, Coulthard P, Worthington HV (2009)
One-stage versus two-stage implant placement. A Cochrane systematic review of randomised controlled clinical trials. Eur J Oral Implantol 2: 91-99.

5. Boioli LT, Penaud J, Miller N (2001) A meta-analytic, quantitative assessment of osseointegration establishment and evolution of submerged and nonsubmerged endosseous titanium oral implants. Clin Oral Impl Res 12: 579588. 